between AD1642 and 1705. And one cannot even appeal to symmetry because the activity in the solar northern hemisphere is slightly different from that in the southern. and at high latitudes solar cycles overlap and it is difficult to tell whether certain features belong to the old cycle or the new one.

Wilson has provided the university student and postgraduate with a perfect mixture of what is known and what is still to be found out. There are detailed discussions about topics such as coronal holes, polar reversals, large-scale fields, nonlinear dynamos, helioseismology, isorotational surfaces, the question of whether the sunspot cycle is chaotic, activity predictions and the general aperiodicity of solar activity. Not only is the book produced, illustrated and referenced to the normal high quality of the Cambridge Astrophysics Series, it is also extremely readable.

David W. Hughes is in the Department of Physics, University of Sheffield, Sheffield S3 $7 R H$, UK.

\section{Nature's chemicals}

\section{Leslie Crombie}

Scent and Fragrances. By Günther Ohloff. Springer: 1994. Pp. 238. DM128, $£ 50.50, \$ 88$.

Natural Products: Their Chemistry and Biological Significance. By J. Mann, R. S. Davidson, J. B. Hobbs, D. V. Banthorpe and J. B. Harborne. Longman: 1994. Pp. 455. £24.99, \$44.95 (pbk).

PLEASANT odours have been one of mankind's indulgences since first recorded time. Ancient Assyrian tablets record that incense was offered to the God of the Sun in Nineveh and that during the reign of Hammurahi a thousand talents $(29,000$ $\mathrm{kg}$ ) were burnt at the Bel-temple of Babylon annually. Throughout the ages, expense has not been spared, and this is still true today. Bulgarian rose oil requires 800 man-hours of labour to pick the 3 tonnes of early morning flowers needed to produce $1 \mathrm{~kg}$ of the oil, which sells for around $\$ 10,000$. It takes eight million jasmin flowers weighing $1,000 \mathrm{~kg}$ to produce $1 \mathrm{~kg}$ of jasmin absolute oil, selling for upwards of $\$ 15,000$.

Of course, this is the exotic and expensive end of the perfumery industry. Application of organic chemistry has allowed identification of the essential odorous components of these plant mixtures and made them available more cheaply in synthetic form. Other cheap raw materials such as petrochemicals and the renewable resources of $\alpha$ - and $\beta$-pinene are today turned into the large quantities of fragrance materials, many of non-natural ori- gin, required by modern society in its household articles such as soap and washing powder.

Scent and Fragrances is a delight to read and I can highly recommend it to chemists with interests in the perfumery industry. Although the large number of chemical formulae may seem at first

IMAGE
UNAVAILABLE
FOR COPYRIGHT
REASONS

Hebrew perfumes - cinnamon, balsam, nard and valerian (twelfth-century Persian manuscript).

sight forbidding, there is much in the book to interest nonchemists also: it is authoritative and written from first-hand experience. Apart from being a much respected organic chemist, Günther Ohloff has long experience of the industry and has contributed substantially to the study of the relationships between chemical structure and odour.

The early part of the book deals with chemoreceptors and structure-odour relationships. There is a certain elusiveness about the latter as the human population is far from uniform in its responses. A study involving six odour types and oneand-a-half million people has revealed some interesting facts. About 1.2 per cent of the population has no sense of smell (total anosmia). Females have a greater odour sensitivity than males, but this can vary during the menstrual cycle, while smoking can intensify certain odours and diminish others. Not surprisingly, odour perception diminishes above the age of 70 , and drastically above 80 . About a hundred compounds are known whose odours are not perceived by part of the population, that is, these people are partially odourblind.

A large part of the book is concerned with odorants from natural sources and the information is concisely yet attractively presented, though in a few places an update is needed because of rapid research progress (such as in the field of the jasmonoids). The author points out the fascinating relationships of named odorants to well-known perfume brands.

In one way or another, many organic chemists - including those working in the perfumery industry -- first become seriously involved with natural products during their postgraduate careers and it would be interesting to know why most standard organic chemistry texts for undergraduates contain so little on this topic. Possibly the vast extent of the subject deters authors. So many specific chemical structures are available as possible illustrative examples that choice becomes bewildering. To control such choice, Natural Products is constructed around seven broad themes: carbohydrates, nucleic acids and their derivatives, amino acids and peptides, fatty acids, terpenoids, phenolics and alkaloids. The themes are handled in different ways by different hands and there is little attempt to coordinate the content or to deal with topics that do not fall into the chosen sections. The book seems best viewed as a compilation of seven monographs under one cover; the continuity and uniformity of judgement displayed by a good singleauthor work is lacking.

Nevertheless, these are all interesting and useful monographs. The choice of themes covers areas of current interdisciplinary interest such as carbohydrates and nucleic-acid derivatives, and I was impressed by the clear account of amino acids and peptides. There are perhaps missed opportunities in the section on fatty acids, where more could have been written on the biosynthetic importance of linoleic and linolenic hydroperoxides in plants, reducing the coverage of some of the well-trodden chemistry of the prostaglandins. The contribution on terpenes reflects the richness of this area for the illustration of organic reactions and their mechanisms, while biosynthetic themes, among others, are dealt with in the accounts of phenolics and alkaloids.

According to the cover, "Natural Products is written for final-year undergraduate and postgraduate students of organic and medicinal chemistry, biochemistry, pharmacy and pharmacology, as well as the professional market". This is a large constituency with differing scientific backgrounds, needs and aspirations, so the content of the book must be something of a compromise. It will be valuable to lecturers and some postgraduates as an information source, but it will seriously overload undergraduates, who need a much less sophisticated introduction to the subject of natural products.

Leslie Crombie is in the Department of Chemistry, University of Nottingham. Nottingham NG7 2RD, UK 